УДК 621.396

\title{
ОЦЕНКА ЧИСЛА ОРТОГОНАЛЬНЫХ СИГНАЛОВ С НЕИЗВЕСТНЫМИ НЕЭНЕРГЕТИЧЕСКИМИ ПАРАМЕТРАМИ*
}

\author{
ТРИФОНОВ А. П., ХАРИН А. В.
}

Воронежский государственный университет, Россия, Воронеж, 394006, Университетская пл., д. 1

\begin{abstract}
Аннотация. Выполнены синтез и анализ алгоритма оценки числа ортогональных сигналов с неизвестными неэнергетическими параметрами по методу максимального правдоподобия
\end{abstract}

Ключевые слова: метод максимального правдоподобия; оценка числа сигналов; укороченная вероятность ошибки; неэнергетические параметры

Необходимость в оценке числа принимаемых сигналов, возникает как при неизвестном числе источников сигналов, так и при неизвестной структуре канала, по которому передается сигнал. Например, в случае использования многолучевого радиоканала в МІМО системах $[1,2]$, число лучей часто оказывается априори неизвестным и его требуется определить. При радиолокационном и акустолокационном (активном или пассивном) наблюдении достаточно распространенной является ситуация, когда число источников сигналов, поступающих на антенную решетку, неизвестно [3-9]. Однако задача оценки числа сигналов на сегодняшний день решена частично.

Возникают трудности в определении структуры алгоритма оценки. Практически отсутствуют результаты теоретического анализа качества функционирования алгоритмов оценки числа сигналов. Более того, нет общепризнанной и корректной количественной харак- теристики таких алгоритмов. Без введения количественных характеристик алгоритмов оценки числа сигналов возникают трудности в сравнении алгоритмов и выборе наиболее эффективного.

В [10] исследована задача оценки числа сигналов с неизвестными амплитудами, при этом предполагалось, что принимаемые сигналы могут быть неортогональными. Амплитуда сигнала является энергетическим параметром [11], поскольку от нее зависит энергия сигнала. В то же время, часто возникает необходимость в оценке числа сигналов, которые содержат неизвестные неэнергетические параметры. К ним относятся время прихода сигнала, его частота, начальная фаза и др.

Ниже рассмотрена задача синтеза и анализа алгоритма оценки числа ортогональных сигналов с неизвестными неэнергетическими параметрами, принимаемых на фоне гауссовского белого шума. Синтез алгоритма оценки про-

* Работа выполнена при поддержке РФФИ (№ 13-01-97504 и №13-08-00735) и Минобрнауки РФ (№ 978).

Электронный вариант статьи: http://radio.kpi.ua/article/view/S002134701508004X

() Трифонов А. П., Харин А. В., 2015 